\title{
La Edad del Jade y la arqueología china
}

\section{The Jade Age and Chinese archaeology}

\author{
TANSIS DARIÉN GARCÍA RUBIO DE YCAZA \\ Universidad de Shandong, \\ Shandong, China \\ tansisy@yahoo.com
}

WALBURGA MARÍA WIESHEU

Escuela Nacional de Antropología e Historia, Ciudad de México, México walburga_enab@yaboo.com

\begin{abstract}
Resumen: Numerosos académicos han señalado las diferencias entre la tradición arqueológica china y otras tradiciones arqueológicas alrededor del mundo. Estas diferencias son el resultado del desarrollo único de la arqueología en China, sus objetivos particulares y su cercana relación con el Estado chino. La Edad del Jade, una propuesta desarrollada al final de los años ochenta y los noventa del siglo XX, es el resultado de la tradición arqueológica china. Este artículo explora las características de la arqueología china y el desarrollo del concepto de la Edad del Jade como consecuencia directa de la misma, desde sus supuestos orígenes en los textos de la dinastía Han hasta su resurrección a finales del siglo pasado, enfatizando su correspondencia con los objetivos y los métodos generales de la arqueología china.
\end{abstract}

Palabras clave: Edad del Jade, arqueología china, Neolítico, jades, periodos arqueológicos. 
Abstract: Many scholars have identified the differences between the Chinese archaeological tradition and other archaeological traditions around the world. These differences are the result of the unique development of archaeology in China, its particular objectives and its close relation with the Chinese State. The Jade Age, a proposal developed at the end of the 80's and in the 90's of the Twentieth Century, is the result of the Chinese archaeological tradition. This article explores the characteristics of the Chinese archaeology and the development of the concept of a Jade Age as a direct consequence of it, from its alleged origins in the ancient texts of the Han dynasty to its resurrection at the end of the past century, highlighting its correlation with the general objectives and methods of the Chinese Archaeology.

Keywords: Jade Age, Chinese Archaeology, Neolithic, jade, archaeological periods

Citar como: García-Rubio de Ycaza, T. D., Wiesheu, W. M. (2022). La Edad del Jade y la arqueología china. Revista Internacional de Estudios Asiáticos, 1(1), 148-183.

Fecha de recepción: 03-09-2021 | Fecha de aceptación: 09-11-2021 


\section{Introducción}

El concepto de "Edad del Jade", entendido no como un periodo mítico sino como una adición al sistema tradicional de Tres Edades, resulta extraño para la gran mayoría de arqueólogos occidentales. Sin embargo entre los arqueólogos chinos especializados en el neolítico y en el origen de la civilización china esta noción ha generado un importante debate sobre el rol del jade durante los mil quinientos años anteriores al inicio de la llamada "Edad del Bronce", esto especialmente a raíz de las múltiples excavaciones arqueológicas realizadas en las últimas décadas, las cuales han arrojado como resultado el descubrimiento de miles de objetos de jade pertenecientes a este periodo. En este artículo nos proponemos analizar el desarrollo del concepto de la "Edad del Jade" no como una simple adición al sistema de Tres Edades de Thomsen, sino como un producto de la tradición arqueológica china, la cual tiene sus propias características y objetivos que permean sus propuestas de manera importante aun cuando sus autores no estén necesariamente conscientes de ello. En el caso de la propuesta de la "Edad del Jade", si es que realmente se está buscando su utilidad como esfuerzo de periodización independiente de la tradición occidental, esta influencia no puede ser simplemente ignorada ya que algunos de sus aspectos más significativos pueden estar vinculados a las tendencias nacionalistas y a los objetivos precisos asociados a la arqueología china.

\section{El descubrimiento de las culturas de jade neolíticas de China}

Los años ochenta y noventa del siglo XX fueron tiempos de profundas transformaciones dentro de China. El caso de su arqueología, tradicionalmente al servicio del Estado e imposible de entender desasociada del mismo, ${ }^{12}$ no fue la excepción. Estos cambios no se pueden calificar como

1 Don D. Fowler, "Uses of the Past: Archaeology in the Service of the State", American Antiquity, no. 2 (1987): 229-248.

2 Walburga Wiesheu, "El Pasado al Servicio del Presente. Interpretaciones Nacionalistas del Surgimiento de la Civilización China", Estudios de Asia y África, no 131 (2006): 365-383. 
una "ruptura", ya que los objetivos y los métodos fundamentales de la arqueología china permanecieron inamovibles, sin embargo, sí permitieron el acogimiento de nuevas propuestas dando lugar a una rápida transformación en la práctica arqueológica en el país. La noción de una Edad del Jade tiene antecedentes claros en trabajos como los de K.C. Chang ${ }^{3}$ y Sun Shoudao, ${ }^{4}$ entre otros arqueólogos, los cuales estaban más que familiarizados con un pasaje del documento clásico de la dinastía Han conocido como Yuejue Shu 越绝书y la posibilidad de una era específica del jade dentro de la secuencia prehistórica de China. No obstante, fue hasta el cambio del paradigma en los años ochenta y noventa y el traslado del origen de la civilización china desde el área central del Río Amarillo a las regiones y culturas anteriormente periféricas del resto de China, que la moderna "Edad del Jade" finalmente vio la luz. Esta nueva "Edad del Jade", a diferencia de aquella de los textos antiguos, ya no se concebía como un periodo mítico sino como una adición al sistema tradicional de Tres Edades del esquema occidental, el cual, no sin controversia, es considerado frecuentemente como el desarrollo "convencional" de las culturas antiguas. ${ }^{5}$

3 Kwang Chih Chang, "Zhongguo Xinshiqi Wenhua Duandai 中国新石器 文化断代 (Cronología de las Culturas del Neolítico en China)", Lishi Yuyan Suojikan, no 30 (1959): 259-309. Kwang Chih Chang, "Tan "Cong" Jiqi Zai Zhongguo Gushishang de Yiyi 谈 “琮” 及其在中国古史上的意义 (Sobre el Significado del "Cong" en la Historia Antigua de China)", Wenwu Chubanshe Chengli SanShi Zhou Nian Jinian (Beijing: Beijing Wenwu Chubanshe 1987), 252-260.

4 Sun Shoudao, "Lun Zhongguo Shishang Yubing Shidai de Tichu-Hongshan Wenhua Yuqi Yanjiu Zhaji 论中国史上玉兵时代的提出-红山文化玉器研究 札记 (Con Respecto a la Propuesta de una Edad Histórica de Armas de Jade para China- Apuntes sobre los Jades de la Cultura Hongshan)", Liaoning Wenwu, no 5(1983): 8-9.

5 Glyn E. Daniel, The Three Ages. An Essay on Archaeological Method (Cambridge: Cambridge University Press 1943). El autor realiza muy buen recuento de los usos y abusos que la propuesta de Tres Edades de Thomsen ha sufrido desde su creación en 1836 hasta mediados del Siglo XX. Estas críticas, a nuestro parecer, continúan vigentes el día de hoy. 
Aunados a los cambios teóricos dentro de la arqueología china de los ańos ochenta y noventa que dieron lugar a la propuesta de la Edad del Jade, los descubrimientos arqueológicos acaecidos durante esas dos décadas no solamente revolucionaron el entendimiento sobre el Neolítico como periodo clave en la evolución cultural de China, sino que además sacaron a la luz algunos de los entierros con los objetos de jade más espectaculares identificados hasta la fecha. Estos hallazgos fueron fundamentales para la creación de la nueva "Edad del Jade" ya que conformaron la evidencia empírica sobre cuya base se gestó el debate concerniente a la existencia de esta era prehistórica. Entre los descubrimientos más importantes cabe mencionar específicamente las excavaciones realizadas en el sitio de Niuheliang, perteneciente a la cultura Hongshan (4500-3000 BCE), en la provincia de Liaoning en el noreste de China, ${ }^{6}$ en donde se identificaron varias tumbas de personajes que han sido interpretados como "chamanes", mismos que fueron enterrados con hasta veinte objetos de jade en diferentes formas. Entre éstos destacan los famosos zhulong 猪龙 o cerdos-dragón, los dragones en forma de "C", brazaletes, tubos para el cabello, peinetas con diseño de máscara teratomorfa, además de múltiples diseños animales como aves, cigarras, tortugas y otros. Dichos artefactos de jade de la cultura Hongshan han sido datados aproximadamente para el 3500 a.C. y son considerados como evidencia del primer gran auge de los objetos tallados en jade en China, aunque de ninguna manera deben ser tomados como los jades más antiguos de ese país, ya que dicho honor pertenece a los jades ornamentales (anillos para las orejas, cuentas, pequeños discos, etc.) hallados recientemente en el sitio de Raohe Xiaonanshan en la provincia de Heilongjiang, también en el noreste de China, los cuales fueron datados en torno al periodo entre 7200-6600 a.C., es decir, más de tres mil años antes que aquellos del sitio de Niuheliang. ${ }^{7}$

6 Guo Dashun, Hongshan Wenhua 红山文化 (La Cultura Hongshan) (Beijing: Wenwu Chubanshe, 2005).

7 Li Youqian et al., "Heilongjiang Raohe Xian Xiao Nanshan Yizhi III Qu Fajue Baogao 黑龙江饶河小南山遗址 III 区发掘报告 (Reporte de las Excavaciones en el Área III del sitio de Xiao Nan Shan, Condado de Raohe)", Kaogu, no 8 (2019): 3-20. 
Otro descubrimiento trascendental fue el realizado en 1987 por Zhang Jingguo en el sitio de Lingjiatan, en la provincia de Anhui. ${ }^{8}$ Las excavaciones en este sitio arrojaron como resultado el descubrimiento de varias tumbas datadas en el periodo de 3500-3300 a.C., en las cuales se identificaron cientos de objetos de jade en múltiples formas que incluyen instrumentos y armas como las hachas yue 钱y $f u$ 斧, además de brazaletes $z h u o$ 镯y buan 环, pendientes buang 璜en diversas formas, incluyendo piezas zoomorfas tales como conejos y tigres, anillos, discos $b i$ 璧, dobles discos entrelazados, cuentas esféricas, cuentas tubulares, objetos en forma de pagoda y de botón, placas en forma de corona, y otros aún más distintivos como figurillas antropomorfas, caparazones de tortugas, animales míticos y, probablemente el más importante de todos, la placa de la tumba $87 \mathrm{M} 4$ encontrada entre dos objetos de jade, uno en forma de caparazón y el otro de plastrón, que presenta una imagen incisa con el diseño de la "estrella de ocho puntas"(bajiaoxingwen八角形纹).

Aún más al sur, en el área del Lago Tai, en las actuales provincias de Zhejiang y Jiangsu y el área municipal de Shanghai, se identificó la cultura Liangzhu, datada en torno al periodo de 3300-2300 a.C., la cual se estableció durante las décadas de los ochenta y noventa del siglo pasado como la cultura del jade más importante del periodo neolítico en China. Los descubrimientos de sus cementerios de élite de Fanshan ${ }^{9}$ y Yaoshan, ${ }^{10}$ entre muchos otros, sacaron a la luz docenas de entierros de personajes de élite que fueron enterrados con cientos de objetos de jade, algunos de

8 Instituto de Arqueología y Reliquias Culturales de la Provincia de Anhui, Lingjiatan-Tianye Kaogu Fajue Baogao Zhi Yi 凌家滩-田野考古发掘报告 (Beijing: Wenwu Chubanshe, 2006).

9 Instituto de Arqueología y Reliquias Culturales de la Provincia de Zhejiang, Liangzhu Yizhi Qun Kaogu Baogao Zhi Er: Fanshan 良渚遗址群考古报告之 二: 反山 (Segundo Reporte de Excavación del Grupo del sitios Liangzbu: Fanshan (Beijing: Wenwu Chubanshe, 2005).

10 Instituto de Arqueología y Reliquias Culturales de la Provincia de Zhejiang, Liangzhu Yizbiqun Kaogu Baogao Zhiyi: Yaoshan 良渚遗址群考古报告之一: 瑶山 (Primer Reporte de las Excavaciones del Grupo de sitios Liangzhu: Yaoshan) (Beijing: Wenwu Chubanshe, 2003). 
los cuales, como los famosos tubos prismáticos cong 琮o los discos bi 璧, han sido descritos como jades "rituales", es decir, que fueron manufacturados explícitamente con el fin de ser utilizados en ceremonias y pueden ser considerados símbolos materiales de las creencias y prácticas religiosas de las sociedad jerárquica de Liangzhu. ${ }^{11}$ El elevado nivel de manufactura de los objetos de jade de la cultura Liangzhu no solamente es atestiguado por la gran variedad de formas, ${ }^{12}$ sino también por la altísima calidad de sus decoraciones.

Los descubrimientos arqueológicos en una serie de sitios de las culturas Hongshan, Lingjiatan y Liangzhu logrados en los años ochenta y noventa fueron, sin lugar a dudas, los que en mayor medida estimularon la formulación de la noción de la Edad del Jade para el último periodo prehistórico de China, que abarca el periodo final del Neolítico tardío y todo el Neolítico Terminal, ${ }^{13}$ es decir, el lapso de tiempo comprendido entre aproximadamente el 3500 y el 2000 a.C. El día de hoy, después de décadas de estudio, hay un panorama más completo del uso del jade en China durante esta temporalidad, el cual, lejos de reducir la validez del debate sobre la "Edad del Jade", ha redundado en aumentar su relevancia y pertinencia. Para dar ejemplo de esto, podemos mencionar los jades hallados en los sitios de Luojiabailing, Jiaoliuhe, Xiaojiawuji ${ }^{14}$ y Tanjialing ${ }^{15}$

11 Walburga María Wiesheu y Tansis Darién García Rubio de Ycaza, "El mundo simbólico de los jades Liangzhu en China”, Cuicuilco, en prensa.

12 Jiang Weidong. Yuqi de Gushi 玉器的故事 (Una Historia de Jades) (Hangzhou: Hangzhou Chubanshe, 2013).

13 Cabe aquí aclarar que nosotros hemos denominado todo el periodo del tercer milenio a.C. como Neolítico Terminal, que muchos arqueólogos todavía clasifican bajo el término de Neolítico Tardío, lo cual puede dar lugar a muchas confusiones.

14 Museo de Jingzhou, Shijiahe Wenbua Yuqi 石家河文化玉器 (Jades de la Cultura Shijiabe) (Beijing: Wenwu Chubanshe, 2008).

15 Museo de Jingzhou Provincia de Hubei. Tianmen Shijiabe Kaogu Fajue Baogao Zhi San: Tanjialing 天门石家河考古发掘报告之三: 谭家岭 (Tercer Reporte de Excavaciones del Sitio de Tianmen, Shijiahe: Tanjialing) (Beijing: Wenwu Chubanshe, 2011). 
en la provincia de Hubei, los cuales han demostrado la altísima calidad de trabajo de los artesanos del jade de la cultura Hou Shijiahe para el periodo 2200-1800 a.C. aproximadamente. Estos objetos mostraron una gran variedad de formas como cabezas de tigres, aves, seres humanos con rasgos animales, cigarras, tubos, entre muchos otros, y fueron hallados casi exclusivamente dentro de urnas mortuorias.

Durante el periodo 3000-2000 a.C., la cultura Shixia, ${ }^{16}$ ubicada en la provincia de Guangdong, también produjo objetos de jade entre los cuales se han podido identificar tubos cong 琮, discos $b i$ 璧y aros buan 环 tan semejantes a los de la cultura Liangzhu que se ha argumentado una cercana relación entre ambas culturas a pesar de los varios cientos de kilómetros que las separan. De la cultura Longshan de Shandong, fechada en el periodo entre 2600-2000 a.C. aproximadamente, no se han encontrado gran cantidad de jades, sin embargo, algunos de los pocos objetos de jade localizados en tumbas de élite de los sitios de Liangchengzhen y Xizhufeng destacan por su altísimo nivel de manufactura, por lo que se infiere que su producción debió ser mucho mayor a lo actualmente registrado en contextos arqueológicos. ${ }^{17} \mathrm{La}$ presencia de jades entre las culturas de la Llanura Central es reducida, aunque existen importantes ejemplos de jades en sitios como Taosi, localizado en el condado de Linfen, en la Provincia de Shanxi, en el cual se localizaron jades en forma de tubos cong 琮, hachuelas, discos bi 璧y buan 环, etc. ${ }^{18}$ Por su parte, en el sitio de Shimao, ${ }^{19}$ localizado en el condado de Shenmu, provincia de Shaanxi, datado en el periodo 2300-1800 a.C., se han descubiertos jades en contextos

16 Instituto de Arqueología y Reliquias Culturales de la Provincia de Guandong, Museo de Guandong y Museo del Distrito de Qujiang de la Ciudad de Shaoguan Provincia de Guangdong, Shixia Yizbi: 1973-1978 Nian Kaogu Fajue Baogao 石峡遗址: 1973-1978年考古发掘报告 (El Sitio de Shixia: Reporte de las Excavaciones de los Años 1973-1978) (Beijing: Wenwu Chubanshe, 2014).

17 Zhang Minghua. Gudai Yuqi 古代玉器 (Jades Antiguos) (Beijing: Wenwu Chubanshe, 2006).

18 Gong Xiexi, ed. Linfen Taosi Yizhi Yanjiu临汾陶寺遗址研究(Investigaciones del Sitio de Taosi, Linfen) (Beijing: Kexue Chubanshe, 2007)

19 Sun Zhouyong et al. "The first Neolithic Urban Center on China's North Loess Plateau: The Rise and Fall of Shimao", Archaeological Research in Asia, no 14 (2018): 33-45. 
funerarios de élite y como ofrendas, incluyendo aquellas que fueron colocadas dentro de los muros y murallas de la ciudad. Finalmente, la cultura Qijia (2300-1500 a.C.), ubicada sobre el cauce superior del Río Amarillo, produjo miles de objetos de jade que claramente tienen fuerte influencia de las culturas Hongshan, Liangzhu y Longshan. ${ }^{20}$

Todos estos ejemplos, haciendo hincapié en que no son los únicos, son suficientes para argumentar que la discusión sobre el concepto de la Edad del Jade continúa siendo pertinente dentro de los estudios del Neolítico chino y lo seguirá siendo en el futuro próximo. A continuación, introduciremos las características fundamentales de la arqueología china y de la noción de la "Edad del Jade", para después describir la cercana relación y la correspondencia entre las dos. Se pondrá en evidencia cómo las características y objetivos específicos de una tradición académica son determinantes en la producción de conceptos tan fundamentales como los periodos arqueológicos y cómo éstos no pueden ser comprendidos desasociados del contexto original en que fueron propuestos.

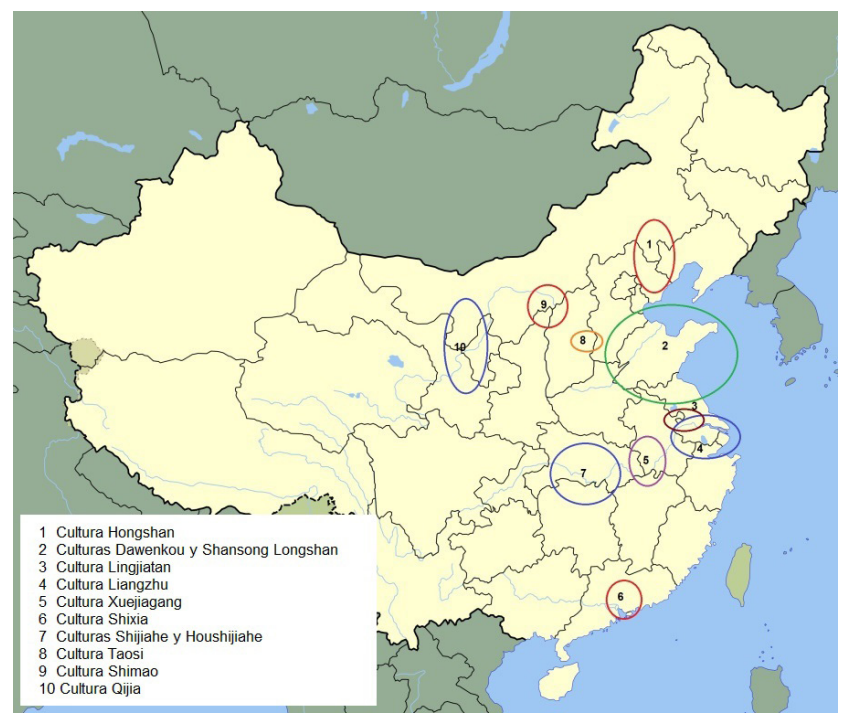

Figura 1.

Mapa de las culturas neolíticas de la llamada "Edad del Jade".

20 Yue Longshan. Qijia Wenhua Yuqi 齐家文化玉器 (Los Jades de la Cultura Qijia) (Beijing: Zhongguo Shudian Chubanshe, 2006). 
García \& Wiesheu | La Edad del Jade

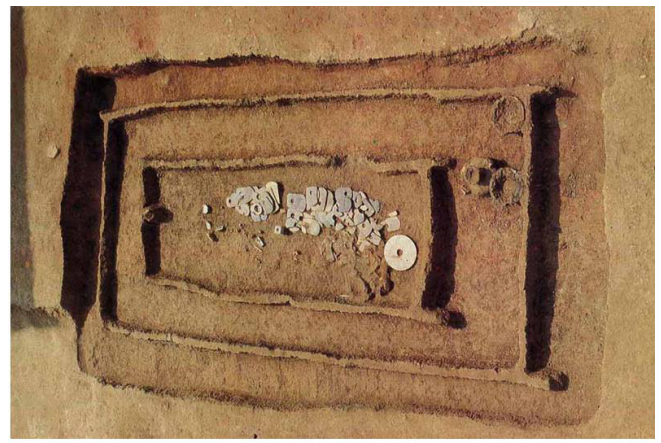

눈

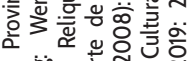

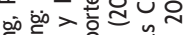
蛋: :

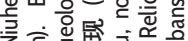

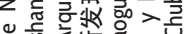

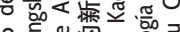

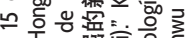

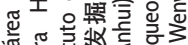

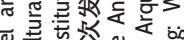

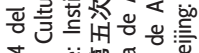

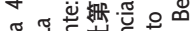

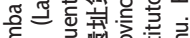

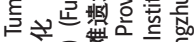

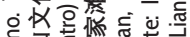

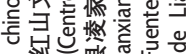

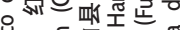

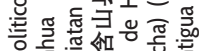

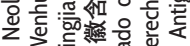

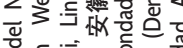

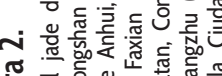

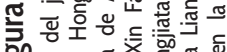
믕

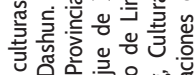

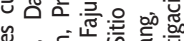

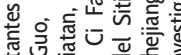
는 :

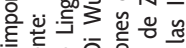

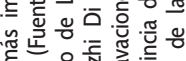

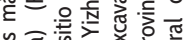

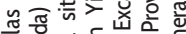
ะ

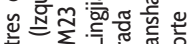
= $\sum^{-5}$ 응 둥워

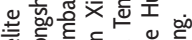

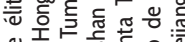

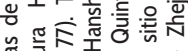
范 है षั

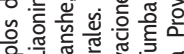

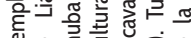

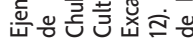




\section{El desarrollo de la arqueología china}

Es comúnmente aceptado que los orígenes de la arqueología china yacen en la combinación de la tradición anticuaria local y la introducción de la arqueología occidental por parte de académicos extranjeros como el sueco Johan G. Andersson (1874-1960) después de la Primera Guerra Mundial, aunado a las contribuciones de arqueólogos chinos como Li Ji (1896-1979) y Feng Hanyi (1899-1977) entre muchos otros, los cuales fueron educados en el exterior y regresaron a China a principios del siglo XX con ideas y métodos contemporáneos de la arqueología occidental. Los objetivos y características de la arqueología china, por su parte, fueron establecidos prácticamente en el mismo momento en que las primeras excavaciones arqueológicas nacionales se llevaron a cabo en el ahora célebre sitio de Anyang, en Henan (1928-1937), en la que fuera la última capital de la dinastía Shang. La arqueología china tomó aspectos como la definición de formas de vasijas y una "aproximación orientada hacia los objetos" de la milenaria tradición anticuaria del país y la combinó con los métodos y técnicas modernas desarrolladas por la arqueología occidental. Debido también a su larga tradición literaria y la gran importancia de ésta, los pioneros de la arqueología china concibieron la arqueología como parte de la historia y como una herramienta que podía ser utilizada para llenar los vacíos dejados por la historiografía tradicional así como para confirmar la confiabilidad de los documentos escritos antiguos ante aquellos que dudaban de su veracidad, como la llamada Yigupai 疑古派 ${ }^{21}$ (Escuela de duda de la antigüedad), la cual es muy representativa sobre todo de la pri-

21 La Escuela de Duda de la Antigüedad nació a principios del siglo XX como respuesta al colapso de la dinastía Qing y el agotamiento del modelo académico tradicional de China. Los académicos más representativos de esta corriente, como Hu Shi o Gu Jiagang, argumentaban la falta de credibilidad científica de los textos históricos tradicionales, sobre todo aquellos que hacían alusión a tiempos anteriores al periodo Zhou. Las excavaciones en el sitio de Anyang y la consecuente confirmación de la información contenida en Los anales históricos de Sima Qian en lo relativo a los últimos nueve reyes de la dinastía Shang ha sido vista como un argumento en contra de la Escuela de Duda de la Antigüedad; sin embargo, el énfasis en el manejo crítico de las fuentes históricas y su enfoque dubitativo de los entendidos históricos tradicionales confucianos ha dejado una profunda marca dentro de la historiografía china. 
mera mitad del siglo XX.$^{22} \mathrm{La}$ arqueología china también nació con otros objetivos específicos: demostrar el origen y desarrollo independiente de la civilización china y comprobar que ésta siempre fue tan avanzada y única como las otras grandes civilizaciones del mundo. Estos objetivos fueron establecidos como reacción a la tesis de Andersson y otros arqueólogos occidentales, los cuales, basados en la temporalidad tardía de la cerámica policroma de Yangshao, concibieron la teoría de la difusión de Occidente hacia Oriente como base del desarrollo de la civilización china.

Después del establecimiento de la República Popular de China en 1949, el marxismo se estableció como el marco teórico fundamental de la gran mayoría de los estudios arqueológicos. Independientemente, como ha sido señalado anteriormente, ${ }^{23}$ esto no significó un cambio esencial en los objetivos y métodos de la arqueología china. La terminología marxista fue ampliamente utilizada pero únicamente de manera superficial ya que la mayoría de los estudios se limitaron a repetir postulados marxistas y a confirmarlos de manera mecánica a partir de la información arqueológica sin experimentar un verdadero cambio de fondo. Al mismo tiempo, el papel del Estado como el único patrocinador de la arqueología en China se volvió definitivo. El objetivo principal de la arqueología china se entendió como el de contribuir a la creación de una identidad nacional y promover los intereses del Estado, un objetivo que fácilmente puede ser rastreado hasta nuestros días. ${ }^{24}$

En la década de 1980, junto con las dramáticas transformaciones económicas y políticas del país, una nueva perspectiva fuertemente influenciada por los trabajos del reconocido académico Su Bingqi llegó a modificar la visión

22 Kwang-Chih Chang, "Archaeology and Ancient Historiography", World Archaeology 13, no 2 (1981): 156-169. Lothar Von Falkenhausen, "On the Historiographical Orientation of Chinese Archaeology”, Antiquity, no 67 (1993): 198-217.

23 Walburga Weisheu, "El Pasado al Servicio”.

24 Gideon Shelach-Lavi, "Archaeology and Politics in China: Historical Paradigm and Identity Construction in Museum Exhibitions", China Information 33, no 1 (2018), 23-45. 
tradicional de la historia china que concebía el área central del Río Amarillo como el único foco de desarrollo de la civilización china. Estas nuevas propuestas multifocales conocidas el día de hoy como “Quxi Leixing 区系类 型” (sistemas regionales y tipos culturales) y “Mantian Xingdou 满天星 斗” (El cielo lleno de estrellas) ${ }^{25}$ desembocaron en la creación de institutos regionales y proyectos de investigación enfocados en desarrollos locales que ya no fueron considerados como fenómenos periféricos al desarrollo de la civilización china sino como partes fundamentales de la misma. Este nuevo paradigma multifocal de la arqueología china que resalta las culturas regionales como parte del "gran desarrollo" de la civilización china, y no como simples receptores de los desarrollos irradiados desde el área central del Río Amarillo, también resolvió un problema que había resultado molesto para la arqueología china: el aparente problema de que la dinastía Shang, la primera dinastía histórica corroborada por la arqueología, se desarrolló más de 1500 años más tarde que las civilizaciones más antiguas de Egipto y Mesopotamia. Ahora las culturas neolíticas del noreste de China como la cultura del jade de Hongshan, o las del sur como la de Liangzhu, podían ser consideradas como culturas "chinas", ya que pueden ser interpretadas como desarrollos directamente relacionados con el nacimiento de esa civilización milenaria y, por consecuencia, los orígenes de la civilización china pueden ser rastreados miles de años anteriores a la dinastía Shang en áreas localizadas a cientos o miles de kilómetros de la Llanura Central. De esta manera y siguiendo estas ideas, se ha vuelto especialmente importante el rastrear rasgos culturales específicos de las dinastías Shang y Zhou en las culturas neolíticas del actual territorio chino ya que este ejercicio liga a las dinastías históricas con el pasado remoto. ${ }^{26}$

A pesar de que actualmente no se ha detectado ninguna forma o sistema de escritura completa previa a la de los famosos huesos oraculares de

$25 \mathrm{Su}$, Bingqi. Zhonggguo Wenming Qiyuan Xintan 中国文明起源新探 (Nuevas Exploraciones sobre el Origen de la Civilización China). (Beijing: Renmin Chubanshe, 2013).

26 Lothar Von Falkenhausen, "The Regional Paradigm in Chinese Archaeology", Nationalism, Politics, and the Practice of Archaeology, ed. por P.L Kohl y C. Fawcett (Cambridge: Cambridge University Press, 1995), 198-217. 
Shang Tardío, y a las fuertes críticas que las fuentes historiográficas tradicionales recibieron a principios del siglo $\mathrm{XX}$, los arqueólogos chinos siguen apoyándose firmemente en documentos históricos con el fin de interpretar descubrimientos del Neolítico y de la Edad del Bronce Temprana. ${ }^{27}$ Evidentemente, existe en la actualidad un gran interés dentro de la arqueología china por relacionar las culturas neolíticas con textos históricos específicos y con los grupos étnicos y periodos mencionados en los mismos. La razón para esto reside en el objetivo último de demostrar la antigüedad de la civilización china y la veracidad de las fuentes históricas tradicionales.

Aun con el gran cambio de perspectiva desde el área nuclear del Río Amarillo a otras áreas previamente consideradas como periféricas, y la introducción de nuevas tecnologías y métodos de análisis de vestigios arqueológicos, la interpretación de la información arqueológica en China todavía sigue claramente sujeta a su propia tradición académica con sus objetivos y métodos particulares. La Edad del Jade es un término autóctono, concebido y desarrollado en China, y por consecuencia no puede ser entendido desasociado de su tradición académica ya que tiene claros elementos historiográficos, crea relaciones entre los periodos históricos y datos arqueológicos y también entre culturas localizadas a miles de kilómetros de distancia. Además, percibe el jade como un elemento exclusivo para China y asimismo utiliza y transforma conceptos occidentales con el fin de crear una "Edad" única para la secuencia china que, sin lugar a dudas, enfatiza la particularidad de esta civilización oriental en oposición a las otras civilizaciones antiguas del Viejo Mundo.

27 Ejemplos específicos de debates actuales con respecto a la correlación de las fuentes históricas con sitios o culturas arqueológicas incluyen la supuesta relación de la cultura Erlitou con la dinastía Xia Tardía o la cultura arqueológica de Xinzhai con Xia Temprano, e inclusive se ha llegado al extremo de sugerir que eventos específicos mencionados en las fuentes antiguas, como la reunión de Yu El Grande con sus zbubou 诸侯 (duques o príncipes) (mencionada en el Zuozbuan, un texto del periodo de Zhou Oriental) sucedió en el sitio Longshan de Yuhuicun, localizado en la Ciudad de Bangbu, Provincia de Anhui, etcétera. 


\section{La historia del concepto moderno de la Edad del Jade}

Prácticamente todos los textos en relación con la Edad del Jade concuerdan en que la primera mención de este término proviene del documento de la dinastía Han Yuejue Shu, escrito en el 56 d.C. por Yuan Kang, en el cual un personaje de nombre Feng Huzi explica al Rey de Chu la relación entre materiales y periodos de la siguiente manera:

En los tiempos de Xuanyuan, Shennong y Hexu, las armas para cortar árboles y construir palacios eran de piedra. Al morir, eran venerablemente enterrados. Los sabios seguían los principios espirituales. En los tiempos de Huangdi, las armas fueron hechas de jade para derribar árboles, construir palacios y extraer minerales de la tierra. El jade también tenía cualidades espirituales. Y nuevamente los sabios seguían (el principio espiritual). Al morir, eran venerablemente enterrados. En los tiempos del emperador Yu, las armas se hicieron de bronce para construir ciudades imperiales y construir canales en el Río Amarillo y el Río Yangtze para que desembocaran regularmente en el mar del este. El mundo estaba regulado como el palacio. ¿No era esto debido al poder de los sabios? Hoy, con la creación de las armas de hierro podemos intimidar a los tres ejércitos, el mundo al escuchar esto no se atreve a no someterse. Este es el aspecto espiritual de las armas de hierro. El Rey tiene el poder moral de los sabios (Yuejue Shu, Waizhuan, Ji Baojian, 1966:3, vol. 2 juan 11).

Lejos de convertirse en un concepto de uso común dentro de la historiografía china, la idea de que existió un periodo en el que "el jade fue utilizado para crear armas y herramientas y tuvo cualidades espirituales" no fue discutido por dos mil años hasta que Guo Baojun recuperó el fragmento mencionándolo en su Guyu Xinquan, publicado en 1946. ${ }^{28}$ Algunos años después, K.C. Chang dividió el periodo neolítico en dos edades diferentes: la “Edad de Piedra Regular” (putongshiqishidai普通石器时代) y la “Edad de Jade y Piedra” (yuqishiqishidai玉器石器时代). Ésta fue la primera vez que K.C. Chang destacó la importancia del jade en general (y

28 Lu Jianying. “Guanyu “Yuqi Shidai” de Zai Sikao 关于” 玉器时代” 的再 思考 (Reconsiderando la Edad del Jade), "Shaoguan Xueyuan Xuebao 29, no 2 (2008): 48 . 
de algunos objetos de jade en particular) para la fase final del Neolítico, considerando oportuno el establecimiento de una "Edad" diferente a la Edad de Piedra convencional. El mismo autor propuso en 1986 el término de la "Edad del Cong de Jade", la cual supuestamente representa la naturaleza chamanística del uso del jade en el Neolítico Terminal. ${ }^{29}$ Sun Shoudao, uno de los arqueólogos a cargo del descubrimiento y excavación de la famosa cultura neolítica de Hongshan, también discutió la posibilidad de una "Edad de las Armas de Jade" (yubingshidai玉兵 时代) datada para el Neolítico Tardío, basándose nuevamente en la cita del arriba mencionado Yue Jue Shu. ${ }^{30}$ La importante académica Deng Shuping, por su parte, propuso el término de "Edad de las Armas de Jade” (yubingshidai玉兵时代) después de analizar las colecciones de jades Liangzhu en el Museo del Palacio de Taipei. ${ }^{31}$

Como podemos ver, para finales de la década de 1980, la idea de una edad particular para la trayectoria cultural china relacionada con el jade ya estaba bien establecida dentro de la academia de ese país, sin embargo, no fue sino hasta 1990 que el nombre, las características y los objetivos del concepto de la Edad del Jade fueron finalmente constituidos en un artículo de Mou Yongkang y Wu Ruzuo, titulado "Discusión Preliminar sobre la Edad del Jade-Explorando los Orígenes de la Civilización en China". ${ }^{32}$ Estos dos autores no solamente definieron la Edad del Jade como una adición particular para China al sistema clásico de Tres Edades desarrollado por Thomsen en Europa del Norte, sino que también establecieron una serie de características que la harían diferente a la Edad de Piedra previa y a la Edad de Bronce posterior, haciendo especial énfasis en la relación

29 Kwang Chih Chang, "Zhongguo Xinshiqi”.

30 Kwang Chih Chang, "Tan "Cong” Jiqi”.

31 Sun Shoudao. "Lun Zhongguo Shishang".

32 Deng Shuping, “You “Juedi Tiantong” dao “Goutong Tiandi” 由“绝地天通” 到“沟通天地” (De la "Ruptura entre el Cielo y la Tierra” hasta la "Comunicación entre el Cielo y la Tierra”)," Gugong Wenwu Yuekan, no 10 (1988): 13-31. 
entre la Edad del Jade con los orígenes de la civilización china. ${ }^{33}$ La Edad del Jade ya no describía los tiempos míticos del Emperador Amarillo en el que "el jade fue utilizado para la creación de herramientas y armas y poseía cualidades espirituales"; en su lugar se había transformado en un periodo histórico definido (3500-2000 a.C.) y ahora estaba basada en vestigios arqueológicos de culturas del Neolítico como las de Hongshan, Liangzhu, Longshan, etcétera. La Edad del Jade ya no es vista como parte de un nuevo esfuerzo de periodización sino más bien una adición. Al mismo tiempo, el concepto también incluye ideas de evolución social y cultural como el surgimiento de las ciudades, los orígenes de la escritura y la metalurgia, todos combinados con ideas claramente chinas como el supuesto origen de la civilización china en términos de la creación de su tradicional sistema ritual conocido como “li (礼)".

El concepto moderno de la Edad de Jade establecido por Mou Yongkang y Wu Ruzuo fue apoyado un año después por Qu Shi con algunas modificaciones menores. ${ }^{34}$ Poco tiempo después, el arqueólogo Zhang Jingguo también sumó su apoyo al concepto y además definió parámetros arqueológicos que serían comunes en publicaciones posteriores. ${ }^{35}$ Después de este autor, Yang Juhua publicó otro artículo defendiendo la existencia de la Edad del Jade sobre todo desde la perspectiva de que el uso del jade en sociedades como la Liangzhu representa la prueba definitiva del desarrollo del sistema ritual “ $l i$ (礼) ”, el cual considera el último paso

33 Mou Yongkang y Wu Ruzuo, "Shitan Yuqi Shidai- Zhonghua Wenming Qiyuan de Tansuo 试谈玉器时代-中华文明起源的探索 (Una Discusión sobre la Edad del Jade- En Busca de los Origenes de la Civilización China),” Zhongguo Wenwubao, 1 de 11 de 1990.

34 Mou Yongkang y Wu Ruzuo, "Yuqi Shidai Shuo 玉器时代说 (Sobre la Edad del Jade)”, Zhonghua Wenhua Luntan, no 3 (1994): 31-37. Mou Yongkang y Wu Ruzuo, "A Discussion on the Jade Age”, Exploring China'a Past. New Discoveries and Studies in Archaeology and Art, ed. por Roderick Whitfield y Wang Tao (London: Safrron, 1999), 41-44.

35 Qu Shi. Zhongguo Yuqi Shidai 中国玉器时代 (La Edad del Jade de China) (Shanxi: Renmin Chubanshe, 1991). 
en dirección a la cristalización de la civilización china. ${ }^{36}$ En el año 2008, el halo nacionalista que rodea el concepto de la Edad del Jade fue establecido explícitamente por Peng De en su artículo "La Edad del Jade. Mi punto de vista", ${ }^{37}$ en el cual apoya el uso del término como prácticamente un símbolo de la independencia china con respecto a otras tradiciones académicas, especialmente la Occidental.

Desde su propuesta en las décadas de 1980 y 1990, muy pocos académicos occidentales han recibido el concepto de la Edad del Jade con los brazos abiertos. Entre ellos podemos destacar a Elizabeth Childs-Johnson, cuya noción de la Edad del Jade difiere en ciertos aspectos de la visión de Mou Yongkang y Wu Ruzuo. Por su parte, Paola Demattée ${ }^{38}$ y Walburga Wiesheu ${ }^{39}$ también han publicado artículos defendiendo el concepto de Edad del Jade de China argumentando que la explotación del jade creó un nuevo sistema de valores y un nuevo sistema ideológico a finales del Neolítico. Aún más importante, estas dos autoras defienden este término en su calidad de creación académica no occidental y consideran que su rechazo está relacionado con la falta de espacio para categorías extranjeras o étnicas dentro de la academia occidental. Finalmente, John Major y Constance Cook en su libro China Antigua. Una historia, específicamente hacen una división entre el Neolítico y la Edad del Jade, considerando de facto el término Edad del Jade como la manera estándar de división del periodo del Neolítico. ${ }^{40}$

36Zhang Jingguo, "Cong Anhui Lingjiatan Mudi Chutu Yuqi Tan Zhongguo de Yuqi Shidai 从安徽凌家滩墓地出土玉器谈中国的玉器时代 (Discutiendo la Edad del Jade de China a partir de los Jades Excavados en el Sitio de Lingjiatan, Anhui”, Dongnan Wenbua, no 2 (1991): 118-121.

37 Yang Juhua, “Liangzhu Wenhua yu Yuqi Shidai 良渚文化与玉器时代 (La Cultura Liangzhu y la Edad del Jade)", Wenbo, no 4 (1994): 14-18.

38 Peng De, “Yuqi Shidai Zhi Wo jian 玉器时代之我见 (Mi Punto de Vista sobre la Edad del Jade)", Sichuan Wenwu, no 5 (2008): 111-113.

39 Paola Demattè, "The Chinese Jade Age: Between Antiquarism and Archaeology”, Journal of Social Archaeology 6, no 2 (2008): 202-226.

40 Walburga Wiesheu, "Cultura e Industria Lapidaria del Jade en el Neolítico Terminal en China- Consideraciones en Torno al Debate Sobre una Edad del Jade", en El Jade y otras Piedras Verdes. Perspectivas Interdisciplinarias e Interculturales, coord. por Gabriela Guzzy y Walburga Wiesheu (México: INAH, 2012a), 259304. 
Cabe apuntar que no solamente autores occidentales como Jessica Rawson ${ }^{41}$ han demostrado su rechazo al concepto chino de la Edad del Jade. Desde la publicación inicial de Mou y Wu, autores chinos como Zhang Minghua, ${ }^{42}$ Wei Erjian, Gu Fei, ${ }^{43}$ Xie Zhongli, ${ }^{44}$ Lin Huadong, ${ }^{45}$ An Zhimin ${ }^{46}$ y Wei Zhen, ${ }^{47}$ entre otros, han publicado trabajos en los que rechazan el término por varias razones. Los argumentos más comunes están relacionados con que el concepto de la Edad del Jade tiene limitaciones geográficas, ya que el jade fue utilizado de manera importante en el Neolítico Tardío únicamente en algunas culturas de China. Además, según estos autores, la Edad del Jade en realidad no es compatible con el sistema tradicional de Tres Edades basado en cambios tecnológicos.

Entre los muchos artículos sobre la Edad del Jade, el escrito por Chen Xingcan ${ }^{48}$ resulta especialmente interesante, ya que indica que la Edad del Jade no debería ser considerada igual a las edades establecidas para la secuencia europea (piedra-bronce-hierro) que están relacionadas directamente con la producción de armas y herramientas, sin embargo esto

41 John Major y Constance Cook. Ancient China. A History (Routledge, 2017). 42 Jessica Rawson, Chinese Jade from the Neolithic to the Qing (London: The British Museum Press, 1995).

43 Zhang Minghua, "Yuqi Shidai Zhi Wo Jian 玉器时代之我见 (Mi Punto de Vista sobre la Edad del Jade)”, Zhongguo Wenwu Bao, 27 de octubre de 1991. $44 \mathrm{Gu}$ Fei, “Ping “Zhongguo Yuqi Shidai” 评“中国玉器时代”(Critica a la Edad del Jade de China)”, Kaogu, no 6 (1993), 534-535.

45 Xie Zhong Li, "Yuqi Shidai- Yi Ge Xin Gainian de Fenxi 玉器时代-一个新 概念的分析 (La Edad del Jade- Análisis de un Nuevo Concepto)”, Kaogu, no 9 (1994): 832-836.

46 Lin Huadong, "Yuqi Shidai Guankui 玉器时代管窥 (Una Visión sobre la Edad del Jade)", Zhejiang Shebui Kexue, no 4 (1996): 45-48.

47 An Zhimin, “Guanyu “Yuqi Shiqi” Shuode Suyuan 关于 “玉器时期” 说 的溯源 (Sobre las Razones de una "Edad del Jade")," Dongnan Wenbua, no 9 (2000): 31-33.

48 Wei Zhen, ““Yuqi Shidai” Yanjiu Shuping “玉器时代”研究述评 (Una Revisión de los Estudios sobre la "Edad del Jade")", Henan Shehui Kexue 12, no 5 (2004): 129-131. 
no significa que el término sea inútil en el afán de entender relaciones de producción en un periodo específico entre algunas culturas del periodo neolítico en China.

\section{Las Edades del Jade de China}

Los arqueólogos Mou Yongkang y Wu Ruzuo, al igual que Elizabeth Childs-Johnson, han asegurado en múltiples ocasiones ser los "creadores" de la "Edad del Jade", sin embargo como bien indica An Zhimin, ${ }^{49}$ es evidente que, si bien las contribuciones de estos autores son, sin lugar a dudas, de alto valor, el concepto de una edad relacionada con el jade para China era una noción que ya se manejaba con frecuencia en ese país desde por lo menos la década de 1950, por lo que es realmente imposible determinar un solo "creador" de esta idea.

Mou Yongkang y Wu Ruzuo en su definición de Edad del Jade ${ }^{50}$ marcaron una diferencia entre jade “ $y u$ 玉” y objetos de jade “ $y u q i$ 玉器”. La primera palabra hace referencia a la piedra únicamente y la segunda a la piedra después de haber sido trabajada y pulida. La definición de “yuq $i$ 玉 器” también incluye los valores sociales de belleza y moral asociados a la piedra, además de la tecnología necesaria para la explotación y manufactura de estos objetos. Como consecuencia de esta definición, la mera aparición de objetos de jade no puede ser considerada como evidencia de una Edad del Jade. El concepto de Edad del Jade está ligado al desarrollo del "jade ritual" entendido como la representación física de un sistema ritual y una sociedad compleja con marcada estratificación. El mejor ejemplo es evidentemente el de la cultura Liangzhu, en la cual, de acuerdo con Mou y Wu, la presencia desigual de jades dentro de las tumbas indica no solamente el alto grado de complejidad social sino también el alto grado de desarrollo agrícola y de producción de otros bienes. El jade también

49 Chen Xingcan, "Yuqi Shidai yu Qingtong Shidai- Zailun Zhongguo Wenming Qiyuan 玉器时代与青铜时代-再论中国文明起源 (La Edad del Jade y la Edad del Bronce- Reconsideración del Origen de la Civilización China”, Kaogu Qiuzhiji (Beijing: Beijing Social Science Press 1996)

50 An Zhimin, "Guanyu "Yuqi Shiqi". 
es visto como un "shenqi 神器”, un objeto sagrado o con cualidades espirituales que permite a los chamanes llevar a cabo sus rituales, los cuales a su vez son la base de su autoridad. Como resultado de esto, la producción y distribución del jade fueron fuertemente restringidas y todas las actividades económicas relacionadas debieron tener gran importancia en la sociedad. La construcción de grandes plataformas de sacrificio y templos también es evidencia arqueológica de la importancia de los rituales dentro de estas culturas del jade. Otras características de la Edad del Jade identificadas por Mou y Wu son el desarrollo de la escritura y la aparición de ciudades entendidas como centros económicos y culturales de entidades políticas regionales en las que se puede identificar la presencia de individuos especializados no comprometidos en labores agrícolas o de subsistencia. Las dos últimas características que estos dos autores identifican en la Edad del Jade, además de la aparición de la metalurgia, son el surgimiento del uso de ataúdes interiores y exteriores y el sacrificio humano como testimonios del aumento de la desigualdad social.

La definición de Qu Shi de la Edad del Jade le adhiere nuevos elementos con claro tono marxista ${ }^{51}$. Este autor añade que el descubrimiento de sacrificios humanos y cuerpos sin tratamiento funerario en sitios arqueológicos de este periodo es evidencia del incremento en la lucha de clases y de una sociedad esclavista. Qu Shi también señala que el uso de jade debe ser entendido como un indicio del establecimiento de un sistema ritual que también se vio reflejado en la construcción de múltiples plataformas y templos. ${ }^{52}$ La Edad del Jade es definida por el establecimiento de sociedades patriarcales, el desarrollo de la propiedad privada y la desigualdad social, la adquisición hereditaria del poder, la invención y propagación de la escritura y el establecimiento de centros con alta densidad poblacional.

51 Mou Yongkang y Wu Ruzuo, "Yuqi Shidai Shuo...”, Mou Yongkang y Wu Ruzuo, "A Discussion on the".

$52 \mathrm{Qu}$ Shi, "Zhongguo Yuqi Shidai ji Shehui Xingzhi de Kaoguxue Guancha 中国玉器时代及社会性质的考古学观察(Observaciones Arqueológicas sobre la Edad del Jade en China y sus Características Sociales)", Jiangnan Kaogu, no 1 (1992): 41-55. 
La Edad del Jade es el nexo entre la Edad de Piedra y la Edad de Bronce, el momento en que los desarrollos del norte, este y sur de China se empezaron a combinar en el área central del Río Amarillo para dar inicio a la cultura de la dinastía Xia y a la civilización de ese país.

La definición de Zhang Jingguo de la Edad del Jade ${ }^{53}$ sigue en la mayoría de sus aspectos a la de $\mathrm{Mou}$ y Wu, sin embargo, añade que el jade representa al menos el 60\% de los bienes encontrados dentro de las tumbas de élite del periodo y que se dio el cambio entre la adoración a fenómenos naturales, o de la naturaleza como fenómeno abstracto, a la adoración de espíritus de carácter individual.

Además de los académicos chinos, algunos sinólogos occidentales también han expresado sus propias versiones de lo que representa la Edad del Jade. Elizabeth Childs-Johnson sugiere, por ejemplo, que el jade es el símbolo material de los grandes logros culturales y el poder alcanzado durante el Neolítico Tardío (3500-2000 a.C.) y que las culturas que explotaron este material en las costas de China sobresalieron en términos de riqueza y liderazgo en comparación con el resto de culturas contemporáneas que "carecieron" de la capacidad de trabajar el jade. ${ }^{54}$ Esta autora concibe un tipo de secuencia entre las culturas Hongshan, Liangzhu, Longshan de Shandong y Erlitou como los centros primarios que impactaron en la civilización china a finales del Neolítico, cada uno ligado de cierta manera a un tipo de valor social adjudicado al jade y a una organización social en específico. ${ }^{55}$ De acuerdo con Childs-Johnson, la secuencia de uso del jade durante la Edad del Jade empieza con la función como "amuleto" por parte de la cultura Hongshan, que a su vez representa la organización social del tipo cacicazgo o jefatura; sigue con el uso del jade como objeto ritual durante la cultura Liangzhu, la cual representa la organización de tipo Ciudad-Estado; continúa con el uso del jade como insignia durante el periodo Longshan representativo de la organización del tipo "Estado

$53 \mathrm{Qu}$ Shi, “Zhongguo Yuqi”.

54 Zhang Jingguo. "Cong Anhui Lingjiatan”.

55 Elizabeth Childs-Johnson, "Jade, as Material". Elizabeth Childs-Johnson, "The Jade Age Revisited". 
Defensivo"; y termina con los jades de la cultura Erlitou en la que el bronce sustituyó al jade como el material más importante.

La defensa de Paola Dematté de la Edad del Jade está basada en la idea de que la manufactura de los objetos de jade puede ser entendida como una nueva tecnología con profundo impacto sociopolítico. La rareza del jade, la dificultad en la producción de objetos y su limitada distribución pudieron haber provocado la creación de un sistema de valores basado en el jade y de una nueva ideología. Dematté considera que las culturas que hicieron uso del jade en este periodo experimentaron un incremento exponencial en términos de complejidad social, cultural y económica, y además los jades también pudieron haber resultado claves para las élites en su afán de adquirir y mantener el control social. Por consecuencia, la categoría de "Edad del Jade" puede resultar útil para entender las dinámicas de este periodo. ${ }^{56}$

Finalmente, con el afán de resumir estas múltiples y diversas definiciones, ¿qué es lo que podemos entender como la Edad del Jade en China? Es claro que la Edad del Jade no representa únicamente una simple adición al sistema tradicional de Tres Edades basado en cambios de índole tecnológico. ${ }^{57}$ La Edad del Jade es un concepto ecléctico que pide prestados postulados funcionales-económicos de los trabajos de Gordon Childe ${ }^{589}$ (por ejemplo las "Edades" corresponden a grosso modo con niveles de desarrollo económico, cada edad nueva es consecuencia de una revolución económica por lo que cada edad no solamente representa un periodo tecnológico sino un

56 Elizabeth Childs-Johnson y Gu Fang. "Yuqi Shidai: Meiguo Bowuguan Zang Zhongguo Zaoqi Yuqi 玉器时代: 美国博物馆藏中国早期玉器 (La Edad del Jade: Jades Tempranos de Colecciones de Museos Americanos)" (Beijing: Science Press, 2008).

57 Paola Demattè, "The Chinese Jade Age".

58 Glyn E. Daniel, "The Three Ages".

59 En la voz de Gordon Childe: "I have spent twenty years trying to give [economic and social] values ... to the traditional 'Ages' and to make these archaeological stages coincide with what sociologists and comparative ethnographers recognised as the main stages in cultural evolution" (Childe 1951, p. 22, en Pare, 2009:75) 
periodo tecno-económico), también se sirve de nociones tradicionales del evolucionismo del siglo XIX de Morgan (la escritura o la metalurgia como elementos necesarios para pasar a un nivel cultural más alto en dirección a la "civilización") e inclusive contiene ideas neo-evolucionistas de integración social y las combina con conceptos chinos de civilización como la creación de un sistema ritual $(l i)$.

Christopher Pare explica que la creación de periodos arqueológicos es, sin lugar a dudas, un elemento fundamental en la arqueología ya que provee las estructuras históricas fundamentales sobre las cuales las demás historias se desarrollan. ${ }^{60}$ La periodización hace que la historia se presente con coherencia, enfatiza eventos, estructuras y procesos al mismo tiempo que señala significados. Por otro lado, también tiene lados negativos ya que frecuentemente termina creando discursos dominantes y modelos históricos del tipo "relevos olímpicos", en los cuales el progreso histórico parece ser el trabajo de naciones o grupos específicos, los cuales pasan la estafeta a otros cuando su contribución ha terminado, creando de esta manera un tipo de "historia necesaria" en la que son ignorados naciones, grupos y culturas que no entran dentro de cierta definición del periodo. La Edad del Jade es un concepto ecléctico, sin embargo, tiene el mismo uso y corre los mismos riesgos que cualquier otro esfuerzo de periodización y, por consecuencia, una importante pregunta se vuelve evidente: ¿Por qué los académicos chinos han propuesto la existencia de una Edad del Jade?

\section{La relación entre la Edad del Jade y la tradición arqueológica china}

La Edad del Jade es un término creado sobre ideas específicas con métodos y objetivos particulares que corresponden con los métodos y objetivos generales de la arqueología china. El primer aspecto que debemos señalar es el supuesto origen del concepto "Edad del Jade". La arqueo-

60 Vere Gordon Childe, "Archaeological Ages as Technological Stages”, Journal of the Royal Anthropological Institute of Great Britain and Ireland 74 (Institute of Great Britain and Ireland), № 1/2 (1944): 7-24. 
logía china tiene una tendencia historiográfica muy marcada y entre sus objetivos principales está el probar que los textos antiguos son fuentes históricas fidedignas. ${ }^{61}$ El concepto de Edad del Jade no es una excepción, ya que supuestamente se ha desarrollado a partir del "redescubrimiento" de la idea presentada por Yuan Kang en el Yuejue Shu datado en la dinastía Han. Si revisamos cuidadosamente la fuente original presentada en párrafos anteriores y la comparamos con el concepto actual de Edad del Jade de Mou Yongkang, Wu Ruzuo, o el de Elizabeth Childs-Johnson, se puede distinguir que la Edad del Jade presentada en el texto antiguo y la idea moderna son muy diferentes. Las interpretaciones del texto original son comprensibles desde el punto de vista de la tradición arqueológica china (el periodo de Huangdi es el Neolítico Tardío, el de Yu es la cultura Erlitou, las herramientas de jade para hacer la guerra y cortar árboles son objetos rituales, etc.) sin embargo, la realidad es que, más que el "redescubrimiento" de un concepto, el texto de la dinastía Han es más que nada una inspiración para la construcción de un nuevo concepto. La lectura de las fuentes en las que los tiempos de Yu "El Grande" pueden ser entendidos como el Neolítico sigue la tendencia de las controversiales interpretaciones bastante comunes en China que relacionan culturas arqueológicas con grupos étnicos mencionados en textos antiguos o sitios arqueológicos con eventos específicos mencionados en las fuentes.

Al mismo tiempo, la Edad del Jade no se entiende como parte de una periodización independiente creada en China, sino más bien una adición al sistema tradicional de Tres Edades creada por Thomsen en el siglo XIX. La idea de adaptar modelos occidentales modificados con el fin de demostrar las particularidades de la civilización china cumple con otro más de los objetivos específicos de la arqueología china: el demostrar la singularidad de esta civilización dentro del marco del desarrollo general de las otras civilizaciones antiguas del mundo. Pese a que la incompatibilidad del modelo original de Tres Edades con la Edad del Jade ha sido señalada

61 Christopher Pare, "Archaeological Periods and their Purpose", Construier le Temps. Histoire et Méthodes des Chronologies et Calendriers des Derniers Millénaires Avant Notre ére en Europe Occidentale. Actes du XXX e Colloque International de Halma-Ipel (Lile: UMR 8164, 2006): 69-84. 
en múltiples ocasiones por varios autores, ${ }^{62}$ hasta la fecha ningún artículo ha tratado de definir la Edad de Piedra, la Edad de Bronce y la Edad de Hierro en términos "chinos", ya que únicamente se han enfocado en la Edad del Jade, la cual tiene el propósito de demostrar la particularidad del desarrollo de la civilización china. K.C. Chang, ${ }^{63} \mathrm{Mou} y \mathrm{Wu},{ }^{64}$ Demattè ${ }^{65}$ y Wiesheu ${ }^{66}$ han argumentado correctamente que la Edad de Bronce china tampoco se ajusta al sistema tradicional de las Tres Edades de Thomsen porque el bronce no fue utilizado para la manufactura de herramientas agrícolas sino más bien para crear objetos rituales y de prestigio, sin embargo, este argumento ha sido esgrimido con el fin de defender la posibilidad de la existencia de una Edad del Jade y no con el fin de llevar a cabo un análisis exhaustivo de la idoneidad del sistema de Tres Edades para el caso del desarrollo de la civilización china. Como consecuencia de esto, aún el día de hoy, la Edad del Jade sigue siendo vista como una adición china al sistema de Tres Edades “universal”. De esta manera, la Edad del Jade, en congruencia con la tradición arqueológica china y con los objetivos particulares de la misma, se plantea como un rasgo distintivo de la evolución de la civilización china en el contexto del desarrollo "convencional" de las civilizaciones, haciendo especial hincapié en la singularidad del proceso civilizatorio chino.

El concepto moderno de la Edad del Jade vio la luz en un momento específico en la historia de la arqueología china: el final de los años ochenta y el principio de los años noventa. En esos años la arqueología china estaba dejando definitivamente de centrarse únicamente en las culturas del área del Río Amarillo para, en su lugar, abarcar todos los desarrollos regionales como partes fundamentales en la creación de la

62 Lothar Von Falkenhausen, "On the Historiographical”; Walburga Wiesheu, "El Pasado al Servicio".

63 Jessica Rawson. "Chinese Jade”; Gu Fei. "Ping "Zhongguo”.

64 Kwang-Chih Chang, "Tan "Cong” Jiqi Zai”.

65 Mou Yongkang y Wu Ruzuo, "Yuqi Shidai Shuo”; Mou Yongkang and Wu Ruzuo, “A Discussion on”.

66 Paola Demattè, “The Chinese Jade”. 
civilización china independientemente de su probable filiación étnica diferente. Fue también un momento en que se dio una gran cantidad de descubrimientos extraordinarios en diferentes regiones de China, los cuales obligaron a los arqueólogos a llevar a cabo una completa reevaluación de la complejidad social y el nivel de desarrollo de las culturas más allá del famoso Zhongyuan (Área Central). El concepto moderno de la Edad del Jade se adaptó notablemente bien a ese ambiente académico ya que presentó diversas culturas neolíticas predinásticas de diferentes regiones del actual territorio chino en un desarrollo hasta cierto punto lineal que termina con el establecimiento de la cultura de Erlitou, la hipotética capital tardía de la dinastía Xia y el inicio de la Edad del Bronce en China, terminando así una edad de la civilización china (el mejor ejemplo de esto es quizás la secuencia Hongshan-Liangzhu-Longshan-Erlitou presentada por Elizabeth Childs Johnson). ${ }^{67} \mathrm{El}$ concepto de Edad del Jade enlaza de esta manera varias culturas neolíticas separadas por miles de kilómetros y cientos de años a través del uso del jade como parte de la construcción de la civilización china en concordancia con la idea de que los desarrollos de diferentes regiones de China contribuyeron al surgimiento final de la civilización china en la cuenca media del Río Amarillo.

Las características de la Edad del Jade están relacionadas no solamente con cuestiones tecnológicas como el sistema de Tres Edades de Thomsen, sino que hacen referencia a lo que normalmente entenderíamos con el inicio de la "civilización". Algunos de estos aspectos se basan en postulados clásicos del evolucionismo de Morgan, como el origen de la escritura o el desarrollo de la metalurgia; otros remiten más a conceptos modernos de la evolución de la integración social como la "diferenciación entre lo urbano y lo rural" o el establecimiento de "centros políticos y económicos"; $y$, finalmente, otros aspectos están relacionados directamente con el concepto chino del origen de la civilización como la creación del sistema ritual “ $l i$ ” (礼), el cual se vio reflejado en la manufactura de ciertos tipos especiales de objetos como los discos $b i$ 璧o los tubos prismáticos cong 琮, y en el papel especial del jade como la piedra que materializó el nuevo 67 Elizabeth Childs-Johnson y Gu Fang. "Yuqi Shidai: Meiguo”. 
liderazgo político y sagrado de los chamanes. Es posible discernir de esta manera que todos estos elementos de la Edad del Jade no están únicamente relacionadas con el uso del jade como una nueva tecnología sino también con el origen de la civilización china como tal. La Edad del Jade establece, de esta manera, un periodo diferente al Neolítico "convencional" en el que se puede argumentar el origen de la civilización china a través de las contribuciones de varias culturas, las cuales ya no se entienden en un estadio evolutivo "inferior" de acuerdo con la clasificación original de las Tres Edades (esto en comparación de aquellas de Egipto o Mesopotamia), sino en un periodo singular característico para China que permite rastrear el origen de la civilización china hasta por lo menos 5000 años atrás.

Para terminar esta sección, y regresando brevemente al texto de Christopher Pare, ${ }^{68}$ un periodo arqueológico puede ser entendido como una estructura sobre la cual las historias encuentran coherencia. Al mismo tiempo, también puede representar una gran transformación en la cual todos los aspectos de la vida están sujetos al cambio. Siguiendo esta idea, la propuesta de la Edad del Jade no solamente aborda la innegable importancia del jade y su profundo impacto sobre varias de las culturas de finales del Neolítico, sino que también provee una nueva estructura particular para China en la cual el surgimiento de la civilización puede ser entendida de acuerdo con las características específicas de la arqueología china.

\section{Observaciones finales}

A pesar de las significativas diferencias entre diversos autores sobre las características particulares de la Edad del Jade, este concepto comparte en gran medida los elementos y objetivos más importantes de la tradición académica china de los años ochenta y noventa del siglo pasado. La Edad del Jade está construida sobre el cambio de paradigma de la arqueología china que permitió vislumbrar todas las culturas de su actual territorio como activas contribuidoras y agentes fundamentales en el desarrollo de la civilización china. Al igual que la arqueología china, el concepto de Edad del Jade combina ideas occidentales con ideas nativas que incluyen

68 Christopher Pare, "Archaeological Periods". 
objetivos particulares como demostrar la singularidad de la civilización china entre las civilizaciones antiguas primarias y su antigüedad milenaria semejante. Paola Demattè y Walburga Wiesheu han indicado de manera provocativa que no hay una manera de periodización de la historia humana que sea completamente "científica" ${ }^{69}$ y, además, que existe una tendencia clara en el Occidente de desechar cualquier noción académica no occidental. Cualquier esfuerzo de periodización necesariamente tendrá sus ventajas y sus desventajas y la Edad del Jade no es la excepción. No pocos autores han encontrado en la propuesta de la Edad del Jade una herramienta útil que les ha permitido profundizar en las dinámicas sociales y económicas de varias culturas del neolítico tardío en las que el jade tuvo un rol fundamental. Como señala Chen Xingcan, ${ }^{70}$ el concepto de la Edad del Jade tiene el potencial de mejorar el entendimiento sobre el Neolítico Tardío y Terminal para algunas de las culturas de la llamada zona costera (haidai 海岱) de China, así como sobre temas relacionados con el jade y sus múltiples e importantísimos roles sociales, económicos y rituales. Por otro lado, la Edad de Jade no puede ser entendida y aceptada como una simple adición al sistema de Tres Edades tradicional, aislada de la tradición académica que le dio forma, la cual claramente tiene objetivos y métodos particulares que permean sus productos dentro de nociones de carácter nacionalista que terminan tergiversando información en aras de alcanzar sus objetivos no científicos. Los riesgos de los esfuerzos de periodización mencionados por Pare ${ }^{71}$ igualmente son aplicables a la Edad del Jade, como la reducción de algunos de los logros culturales más importantes del periodo (como la cerámica negra ultra fina conocida como "cáscara de huevo" de la cultura Longshan de Shandong, o el desarrollo de culturas enteras como Qujialing/Shijiahe del curso medio del Río Yangtzé), a papeles secundarios debido a no tener relación con

69 Paola Demattè, "The Chinese Jade”; Walburga Wiesheu, "La reintroducción de una noción antigua: ¿existió una Edad del Jade en la trayectoria cultural del surgimiento de la civilización china?”, en Temas de Historia de China, editado por Romer Cornejo (México D.F.: El Colegio de México 2012b), 19-64.

70 Chen Xingcan, "Yuqi Shidai".

71 Christopher Pare, "Archaeological Periods". 
el jade. Sin embargo, este tipo de problemática no es de ninguna manera exclusiva de la Edad del Jade, sino que corresponde a cualquier sistema de periodización, especialmente aquellos aplicados a la arqueología, la cual depende necesariamente de la identificación de restos materiales.

Los sistemas de periodización en la arqueología son, frecuentemente, la primera frase de introducción dentro de casi cualquier texto arqueológico, por lo que su análisis y estudio es fundamental para el desarrollo de esta disciplina. La "Edad del Jade" es, sin lugar a dudas, una de las más recientes y provocativas propuestas de periodización. Además, las enormes evidencias arqueológicas en relación al uso del jade durante el Neolítico tardío en varias regiones de China se siguen acumulando día con día, por lo que su estudio y evaluación es fundamental. El primer paso con este fin es entender que cualquier propuesta, independientemente de si es creada en el Occidente o en China, es hija tanto de sus autores como de la tradición académica a la cual pertenece. En el caso de la Edad del Jade, como hemos expuesto en este trabajo, es hija de la tradición académica china, con todo lo que esto conlleva.

\section{Bibliografía}

An, Zhimin. “Guanyu "Yuqi Shiqi” Shuode Suyuan 关于 “玉器时期” 说的溯源 (Sobre las Razones de una “Edad del Jade”)". Dongnan Wenhua, no. 9 (2000): 31-33.

Chang, Kwang Chih. "Archaeology and Ancient Histography". World Archaeology 13, no. 2 (1981): 156-169.

Chang, Kwang Chih. "Tan "Cong” Jiqi Zai Zhongguo Gushishang de Yiyi 谈“琮” 及其在中国古史上的意义 (Sobre el Significado del "Cong" en la Historia Antigua de China)". En Wenwu Chubanshe Chengli SanShi Zhou Nian Jinian, 252-260. Beijing: Beijing Wenwu Chubanshe, 1987.

Chang, Kwang Chih. "Zhongguo Xinshiqi Wenhua Duandai 中国新石 器文化断代 (Cronología de las Culturas del Neolítico en China)”. Lishi Yuyan Suojikan, no. 30 (1959): 259-309. 
Chen, Xingcan. "Yuqi Shidai yu Qingtong Shidai- Zailun Zhongguo Wenming Qiyuan 玉器时代与青铜时代- 再论中国文明起源 (La Edad del Jade y la Edad del Bronce- Nueva discusión sobre el Origen de la Civilización China)". Kaogu Qiuzhiji. Beijing: Beijing Social Science Press, 1997.

Childe, Vere Gordon. "Archaeological Ages as Technological Stages". Journal of the Royal Anthropological Institute of Great Britain and Ireland 74 (Institute of Great Britain and Ireland), no. 1/2 (1944): 7-24.

Childe, Vere Gordon. Social Evolution. New York: Schuman, 1951.

Childs-Johnson, Elizabeth y Gu Fang. Yuqi Shidai: Meiguo Bowuguan Zang Zhongguo Zaoqi Yuqi (La Edad del Jade: Jades Tempranos de Colecciones de Museos Americanos). Beijing: Science Press, 2008.

Childs-Johnson, Elizabeth. "Jade, as Material and Epoch". En China. 5000 Years: Innovation and Transformation in the Arts, 55-68. New York: Solomon R. Guggenhelm Museum, 1998.

Childs-Johnson, Elizabeth. “The Jade Age Revisited ca. 3500-2000 BCE”. En The Oxford Handbook of Early China, editado por Elizabeth Childs-Johnson, 101-117. Oxford: Oxford University Press, 2020.

Daniel, Glyn E. The Three Ages. An Essay on Archaeological Method. Cambridge: Cambridge University Press, 1943.

Demattè, Paola. "The Chinese Jade Age: Between Antiquarism and Archaeology”. Journal of Social Archaeology, 6 (2006): 202-226.

Deng, Shuping. "You “Juedi Tiantong” dao "Goutong Tiandi” 由“绝 地天通”到“沟通天地”(De la “Ruptura entre el Cielo y la Tierra” hasta la "Comunicación entre el Cielo y la Tierra")". Gugong Wenwu Yuekan, no. 10 (1988): 13-31.

Falkenhausen, Lothar Von. "On the Historiographical Orientation of Chinese Archaeology”. Antiquity, no. 67 (1993): 198-217.

Falkenhausen, Lothar Von. "The Regional Paradigm in Chinese Archaeology". En Nationalism, Politics, and the Practice of Archaeology, editado por P.L Kohl y C. Fawcett, 198-217. Cambridge: Cambridge University Press, 1995. 
Fowler, Don D. "Uses of the Past: Archaeology in the Service of the State". American Antiquity, no. 2 (1987), 229-248.

Gao, Guangren y Feng Shiluan. Dawenkou Wenbua 大汶口文化 (La Cultura Dawenkou). Beijing: Wenwu Chubanshe, 2013.

Gong, Xiexi, ed. Linfen Taosi Yizhi Yanjiu 临汾陶寺遗址研究 (Investigaciones del Sitio de Taosi, Linfen). Beijing: Kexue Chubanshe, 2007.

Gu, Fei. “Ping “Zhongguo Yuqi Shidai” 评 “中国玉器时代” (Critica a la Edad del Jade de China)”. Kaogu, no. 6 (1993): 534-535.

Guo, Dashun. Hongshan Wenbua 红山文化 (La Cultura Hongshan). Beijing: Wenwu Chubanshe, 2005.

Instituto de Arqueología y Reliquias Cuturales de la Provincia de Anhui. Lingjiatan-Tianye Kaogu Fajue Baogao Zhi Yi 凌家滩: 田野考 古发掘报告之一 (Primer Reporte de las Excavaciones del Sitio de Lingjiatan). Beijing: Wenwu Chubanshe, 2006.

Instituto de Arqueologia y Reliquias Culturales de la Provincia de Guandong, Museo de Guandong, Museo del Distrito de Qujiang de la Ciudad de Shaoguan Provincia de Guangdong . Shixia Yizhi: 1973-1978 Nian Kaogu Fajue Baogao 石峡遗址：1973-1978年考 古发掘报告 (El Sitio de Shixia: Reporte de las Excavaciones de los Años 1973-1978). Beijing: Wenwu Chubanshe, 2014.

Instituto de Arqueología y Reliquias Culturales de la Provincia de Zhejiang. Liangzbu Yizhiqun Kaogu Baogao Zhiyi: Yaoshan 良渚遗 址群考古报告之一: 瑶山 (Primer Reporte de las Excavaciones del Grupo de Sitios de Liangzhu: Yaoshan). Beijing: Wenwu Chubanshe, 2003.

Instituto de Arqueología y Reliquias Culturales de la Provincia de Zhejiang. Liangzhu Yizhi Qun Kaogu Baogao Zhi Er: Liangzhu 良 渚遗址群考古报告之二: 反山 (Segundo Reporte de Excavación del Grupo del sitios Liangzhu: Fanshan. Beijing: Wenwu Chubanshe, 2005 .

Instituto de Arqueología y Reliquias Culturales de la Provincia de Zhejiang. Reporte General de las Investigaciones en la Ciudad Antigua de Liangzhu. Beijing: Wenwu Chubanshe, 2019. 
Jiang, Weidong. Yuqi de Gushi 玉器的故事 (Un Historia de Jades). Hangzhou: Hangzhou Chubanshe, 2013.

Li, Youqian, Yang Yongcai, Song Jiaqi, Xia Hao, Han Wenyan, Chen Kongyang, Zhang Xinwei y Zhang Liniu. "Heilongjiang Rao He Xian Xiao Nanshan Yizhi III Qu Fajue Baogao 黑龙江饶河小南山 遗址III区发掘报告 (Reporte de las Excavaciones en el Ärea III del sitio de Xiao Nan Shan, Condado de Raohe)”. Kaogu, no 8 (2019): 3-20.

Lin, Huadong. “Yuqi Shidai Guankui 玉器时代管窥(Una Visión sobre la Edad del Jade)”. Zhejiang Shebui Kexue, no. 4 (1996): 45-48.

Liu, Bin, Wang Ningyuan y Chen Minghui. "A Realm of Gods and Kings: The Recent Discovery of Liangzhu and the Rise of Civilization in South China”. Asian Archaeology, no 4 (2016): 13-31.

Lu, Jianying, “Guanyu “Yuqi Shidai” de Zai Sikao 玉器时代的再思考 (Reconsiderando la Edad del Jade)". Shaoguan Xueyuan Xuebao 29, no. 2 (2008): 48-51.

Major, John y Constance Cook. Ancient China. A History. Routledge, 2017.

Mou, Yongkang y Wu Ruzuo. "Shitan Yuqi Shidai-Zhonghua Wenming Qiyuan de Tansuo 试谈玉器时代-中华文明起源的探索 (Una Discusión sobre la Edad del Jade- En Busca de los Origenes de la Civilización China)". Zhongguo Wenwubao, 1 de noviembre de 1990.

Mou, Yongkang y Wu Ruzuo. "Yuqi Shidai Shuo 玉器时代说 (Sobre la Edad del Jade)". Zhonghua Wenbua Luntan, no. 3 (1994): 31-37

Mou, Yongkang y Wu Ruzuo. "A Discussion on the Jade Age". En Exploring China'a Past. New Discoveries and Studies in Archaeology and Art, editado por Roderick Whitfield y Wang Tao, 41-44. Saffron, International Series in Chinese Art and Archaeology 1, 1999.

Museo de Jingzhou. Shijiahe Wenhua Yuqi 石家河文化玉器 (Jades de la Cultura Shijiabe). Beijing: Wenwu Chubanshe, 2008.

Museo de Jingzhou Provincia de Hubei. Tianmen Shijiahe Kaogu Fajue Baogao zhi San: Tanjialing 天门石家河考古报告之三: 谭家 岭 (Tercer Reporte de Excavaciones del Sitio de Tianmen, Shijiahe: Tanjialing). Beijing: Wenwu Chubanshe, 2011. 
Pare, Christopher. "Archaeological Periods and their Purpose". En Construier le Temps. Histoire et Méthodes des Chronologies et Calendriers des Derniers Millénaires Avant Notre ére en Europe Occidentale. Actes du XXX e Colloque International de Halma-Ipel, 69-84. Lile: UMR 8164, $2006 .$.

Peng, De. “Yuqi Shidai Zhi Wo jian 玉器时代之我见 (Mi Punto de Vista sobre la Edad del Jade)". Sichuan Wenwu, no. 5 (2008): 111113.

$\mathrm{Qu}$, Shi. Zhongguo Yuqi Shidai 中国玉器时代 (La Edad del Jade de China). Shanxi: Renmin Chubanshe, 1991.

$\mathrm{Qu}$, Shi. "Zhongguo Yuqi Shidai ji Shehui Xingzhi de Kaoguxue Guancha 中国玉器时代及社会性质的考古观察 (Observaciones Arqueológicas sobre la Edad del Jade en China y sus Características Sociales)". Jiangnan Kaogu, no. 1 (1992): 41-55.

Rawson, Jessica. Chinese Jade from the Neolithic to the Qing. London: The British Museum Press, 1995.

Shelach-Lavi, Gideon. "Archaeology and Politics in China: Historical Paradigm and Identity Construction in Museum Exhibitions". China Information 33, no. 1 (2018): 23-45.

Su, Bingqi. Zhonggguo Wenming Qiyuan Xintan 中国文明起源新 探 (Nuevas Exploraciones sobre el Origen de la Civilización China). Beijing: Renmin Chubanshe, 2013.

Sun, Shoudao. "Lun Zhongguo Shishang Yubing Shidai de TichuHongshan Wenhua Yuqi Yanjiu Zhaji 论中国史上玉兵时代的 提出-红山文化玉器研究札记 (Con Respecto a la Propuesta de una Edad Histórica de Armas de Jade para China- Apuntes sobre los Jades de la Cultura Hongshan)". Liaoning Wenwu, no. 5 (1983): 8-9.

Sun, Zhouyong, Jing Shao, Li Liu, Jianxin Cui, Michael F. Bonomo, Qinghua Guo, Xiaohong Wu, Jiajing Wang. "The first Neolithic Urban Center on China's North Loess Plateau: The Rise and Fall of Shimao". Archaeological Research in Asia, no 14 (2018): 33-45. 
Wei, Zhen ““Yuqi Shidai” Yanjiu Shuping “玉器时代”研究述评 (Una Revisión de los Estudios sobre la "Edad del Jade")". Henan Shehui Kexue 12, no. 5 (2004): 129-131.

Wiesheu, Walburga. "El Pasado al Servicio del Presente. Interpretaciones Nacionalistas del Surgimiento de la Civilización China". Estudios de Asia y África, no. 131 (2006): 365-383.

Wiesheu, Walburga. "Cultura e Industria Lapidaria del Jade en el Neolitico Terminal en China- Consideraciones en Torno al Debate Sobre una Edad del Jade". En El Jade y otras Piedras Verdes. Perspectivas Interdisciplinarias e Interculturales, coordinado por Gabriela Guzzy y Walburga Wiesheu, 259-304. México: INAH, 2012.

Wiesheu, Walburga. "La reintroducción de una noción antigua: ¿existió una Edad del Jade en la trayectoria cultural del surgimiento de la civilización china?”. En Temas de Historia de China, editado por Romer Cornejo, 19-64. México D.F.: El Colegio de México, 2012.

Wiesheu, Walburga Maria y Tansis Darién García Rubio de Ycaza. "El mundo simbólico de los jades Liangzhu en China”. Revista Cuicuilco, en prensa, 2021.

Xie, Zhongli. "Yuqi Shidai- Yi Ge Xin Gainian de Fenxi 玉器时代一个新概念的分析 (La Edad del Jade- Análisis de un Nuevo Concepto)". Kaogu, no. 9 (1994): 832-836.

Yang, Juhua. “Liangzhu Wenhua yu Yuqi Shidai 良渚文化与玉器时代 (La Cultura Liangzhu y la Edad del Jade)”. Wenbo, no. 4 (1994): 1418.

Ye, Shuxian. “Qijia Wenhua yu Yuqi Shidai 齐家文化与玉器时代 (La Cultura Qijia y la Edad del Jade)”. Tantao yu Zhenming, no 4 (2008): 23-24.

Yuan, Kang. Yuejue Shu. Vols. 6-7. series 66 vols. Taipei: Baibu Congshu Jicheng, 1966.

Yue, Longshan. Qijia Wenhua Yuqi 齐家文化玉器 (Los Jades de la Cultura Qijia). Beijing: Zhongguo Shudian Chubanshe, 2006. 
Zhang, Jingguo. "Cong Anhui Lingjiatan Mudi Chutu Yuqi Tan Zhongguo de Yuqi Shidai 从安徽凌家滩墓地出土玉器谈中 国的玉器时代 (Discutiendo la Edad del Jade de China a partir de los Jades Excavados en el Sitio de Lingjiatan, Anhui”. Dongnan Wenbua, no 2 (1991): 118-121.

Zhang, Minghua. Gudai Yuqi 古代玉器 (Jades Antiguos).Beijing: Wenwu Chubanshe, 2006.

Zhang, Minghua. "Yuqi Shidai Zhi Wo Jian 玉器时代之我见 (Mi Punto de Vista sobre la Edad del Jade."Z Zongguo Wenwu Bao, 27 de octubre de 1991. 